\title{
Voluntary Carbon Offsetting: Who does it?
}

\author{
Dr Char-lee J. McLennan ${ }^{\mathrm{a}}$ \\ Professor Susanne Becken ${ }^{\mathrm{a}}$ \\ Rod Battye \\ Dr Kevin Kam Fung So ${ }^{\mathrm{a}}$ \\ ${ }^{a}$ Griffith Institute for Tourism, Griffith University, Gold Coast, Australia \\ ${ }^{b}$ Tourism Research Australia, Canberra, Australia
}

Corresponding author:

Char-lee McLennan

E-mail: c.mclennan@griffith.edu.au

Phone: +61 (0) 407589110

'We certify that this is an original work, and that neither this manuscript nor a version of it has been published elsewhere nor is being considered for publication elsewhere.'

\section{Acknowledgements}

The authors would like to acknowledge Tourism Research Australia for providing access and insights into the International Visitor Survey data. 


\title{
Voluntary Carbon Offsetting: Who does it?
}

\begin{abstract}
Voluntary carbon offsetting was popularised during the last decade, particularly by airlines, as a tool to 'neutralise' emissions associated with travel. Although there is a wide range of carbon offsetting schemes for tourism, the uptake of these programs has been reportedly low. Regardless, little research has explored the visitor segments who voluntarily undertake carbon offsetting. Consequently, this research investigates the prevalence of carbon offsetting amongst international tourists to Australia between 2008 and 2010 and, using cluster analysis, segments the carbon offsetters into three distinct markets. Findings reveal a stable carbon offsetting market, despite a Global Financial Crisis occurring during the reference period. Further, travellers from the United Kingdom/Europe were more likely to carbon offset, while those from Asia were less likely to participate in the schemes. Thus, this could indicate that the social marketing, public discourse and substantial media coverage in the United Kingdom/Europe had enhanced climate change mitigation behaviours.
\end{abstract}

Keywords: Carbon offsetting; Segmentation; Environmental behaviour, Emissions 


\section{Voluntary Carbon Offsetting: Who does it?}

\section{Introduction}

The environmental footprint, and more specifically greenhouse gas emissions, of air travel has been the subject of academic enquiry for over a decade (Becken, 2002; Becken, 2007), both in relation to tourist behaviour (Hares, Dickinson \& Wilkes, 2010; Smith \& Rodger, 2009) and destination initiatives (Gössling, 2009). Carbon offsetting as a form to 'neutralise' one's emissions by investing into schemes that reduce atmospheric concentrations of greenhouse gases, for example through reforestation or renewable energy projects, has been a particular research focus (Becken \& Hay, 2012). Gössling et al. (2007) reported on a wide range of carbon offsetting schemes for tourism, challenges associated with them, and their particular relevance to the tourism context. Estimates of the cost of and visitors' willingness to pay into carbon offset schemes, particularly for flights, has been explored by van Birgelen, Semeijn and Behrens (2011) and McKercher, Prideaux, Cheung and Law (2010), amongst others.

The uptake of purchasing carbon credits by tourists, in practice, has been relatively low probably in the order of 2-10\% of travellers (Mair, 2011). There are several reasons for this, including lack of knowledge and understanding of how carbon offsetting works, lack of transparency, and a sense that carbon offsetting represents an easy excuse to continue current behaviours (Becken, 2007). Indeed, it has been identified that a major barrier to offsetting flights is the many different types of carbon calculators in use by companies, which often have simple interfaces but complex, ambiguous and inconsistent calculation processes (Gössling et al., 2007). Nevertheless, a small - yet significant - proportion of tourists have chosen to participate in carbon offsetting and it is important to understand who they are, and whether these markets have remained stable over time.

Earlier research on travellers from the United Kingdom (UK) and Australia found that tourists who purchased carbon offsets were more likely to be male, younger and hold ecocentric attitudes (Mair, 2011). It is useful to analyse those who actually practiced offsetting, rather than those who report they intend to, as the stated versus actual behaviour is likely to reveal a major gap (Ziegler, Schwarzkopf \& Hoffmann, 2012). In a literature review on environment-friendly tourists, Dolnicar, Crouch and Long (2008) argued that research in this area has been limited, with a wide range of conceptualisations of what embodies an environment-friendly tourist. The common denominator of sustainable segments seems to be tourists who are more educated, higher earners, and interested in learning. Also, while there have been efforts in the UK and Europe to undertake social marketing to change behaviour with regard to carbon emission reductions (Burchell, Rettie \& Patel, 2013), there is little evidence that these strategies have been effective in increasing carbon offsetting.

This research focuses on international tourists to Australia who had chosen to offset the greenhouse gas emissions of their travel. Three research questions were asked: 1) did the 
prevalence of carbon offsetting change over the three year period between 2008-2010; 2) who offset compared with those who did not offset; and 3) were the segments of off-setters stable over the three year reference period?

\section{Method}

The International Visitor Survey (IVS), managed by Tourism Research Australia, is Australia's leading source of information on international visitors to Australia. Conducted in four languages, the IVS samples 40,000 departing, short-term international travellers aged 15 years and over who have been visiting Australia each year. The survey is conducted by Computer Assisted Personal Interviewing in the departure lounges of the eight major Australian international airports. Survey results are weighted by country of residence, state of arrival, main purpose of visit, airport of departure and age and sex of the visitor to the overseas arrivals and departures data provided by the Department of Immigration and Border Protection and published by the Australian Bureau of Statistics (Catalogue no. 3401.0).

The IVS collects information on place of residence, repeat visitation, group tours, travel party, transport, accommodation, activities, expenditure and demographics, amongst other key information. The IVS also provides critical psychographic segmentation information for Tourism Australia's marketing campaigns by collecting visitor's agreement or disagreement with five long haul statements about their travel preferences, which are then modelled to identify the 'ideal' visitor segment, coined the "Experience Seeker”. While the actual statements and modelling methodology is sensitive information, the Experience Seeker segment can be broadly classified as experienced international travellers who value authenticity, adventure, learning and immersion in the local culture (Tourism Australia, 2006).

In the calendar years of 2008, 2009 and 2010, the IVS collected information on carbon offsetting to respond to an emerging trend in the tourism industry aimed at addressing climate change. Specifically, the main identifying question in the carbon offsetting supplementary questionnaire, that is central to this research note, asked "Did you make a voluntary carbon offset payment on anything associated with this trip?", with potential responses being either "Yes", "No" or "Don’t Know". The supplementary questions were subject to being "skipped" if the survey was considered to be taking too long by either the respondent or the interviewer.

In total, 3,104 international respondents stated that they had carbon offset an item associated with their trip over the three years the questions were in-field, with an additional 102,838 respondents stating that they did not carbon offset. The IVS is a stratified random sample that uses probability weights. As a result, it is necessary to account for the survey design when undertaking analysis. STATA, unlike SPSS, can account for probability weights in the standard package. Therefore, this analysis accounts for the complex sample design of the IVS by using STATA v.12 with probability weights specified. 
Analysis initially sought to test for significant differences between those who carbon offset and those who did not. As a result of this focus, the respondents who skipped or refused to answer the carbon offsetting supplementary questions, or who did not know whether they carbon offset (a total of 15,964 respondents) were set to missing. While it could be assumed that those who did not know whether they carbon offset did not offset, it is also possible that employers could have offset on behalf of the traveller. Therefore, to avoid imposing assumptions on the data that could lead to bias, the most appropriate treatment for the "Don't Know” respondents was to exclude them from further analysis. Under weighted data, standard statistical tests, such as Pearson chi-square and t-tests do not hold. Therefore to account for the weighting it is necessary to undertake design based f-tests and Adjusted Wald tests. The p-value for the corrected f-statistics in the design based f-test is interpreted in the same way as a p-value for the Pearson chi-square for unweighted data (StataCorp, 2011).

Following this initial analysis, survey logistic regression (a regression method appropriate for binary variables) was used to determine key predictors of carbon offsetting. The regression analysis determined that the significant predictor variables of carbon offsetting were country group, backpacker, age group, nature traveller and experience seeker (See Appendix A). Consequently, these variables were selected as input variables for a two-step cluster analysis. The two-step cluster analysis was undertaken in SPSS v.21 using the respondents who stated that they carbon offset (part of) their trip. The TwoStep procedure automatically generated three clear clusters, with the average silhouette measure of cohesion and separation being 0.4 or a rating of "fair". Once the clusters were selected, the data with the new cluster variable was transferred back into STATA v.12 for further analysis using the probability weights.

\section{Results}

Approximately $2.1 \%$ (or 107,000) of international visitors to Australia carbon offset in 2008, with $2.7 \%$ (or 141,000) offsetting in 2009 and 2.5\% (or 135,000) offsetting in 2010. A design based f-test was carried out on the tabulation of the Carbon Offsetting variable and the three years of collection to determine if there were changes over time. While there was a significant increase in the proportion of visitors carbon offsetting between 2008 and 2009 $(F(1,1318)=24.98, p<0.001)$, there was no significant change between 2009 and $2010(F(1$, $1320)=3.32, \mathrm{p}=0.069)$.

Working with the pooled three years' worth of data, a design based f-test revealed that there was a significant $(F(5.67,7765.92)=71.30, p<0.001)$ difference in those who carbon offset and those that did not by country. Most notably, visitors from the UK were more likely to carbon offset, while visitors from New Zealand and the Asian countries were less likely to carbon offset (Table 1).

\section{<Insert Table 1 about here $>$}


There was a significant difference $(F(4.84,6628.61)=4.92, \mathrm{p}<0.001)$ in age groups between those who did and did not carbon offset, with those aged 20 to 34 years being more likely to carbon offset and those aged 45 to 64 years being less likely to carbon offset. Possibly associated with the age of the respondents, visitors whose marital status was single were significantly more likely than those who travelled as a couple to carbon offset $(\mathrm{F}(1.68$, $2303.12)=23.92, \mathrm{p}<0.001$ ). Those on a group tour were found to be significantly less likely to carbon offset than those travelling independently $(\mathrm{F}(1,1370)=28.03, \mathrm{p}<0.001)$.

In addition, unaccompanied travellers were significantly more likely to carbon offset than any other travel party type $(\mathrm{F}(3.68,5035.17)=13.59, \mathrm{P}<0.001)$, which is most likely related to their increased likelihood of being single and younger. Notably, those whose main purpose of travelling to Australia was for a holiday and employment were significantly more likely to carbon offset than those travelling for business and education $(F(4.61,6316.82)=3.69$, $\mathrm{p}=0.003)$. Nature based visitors were found to be significantly more likely than other visitors to carbon offset $(\mathrm{F}(1,1370)=101.39, \mathrm{P}<0.001)$. For the purpose of this study, a nature based visitor is defined as an international visitor who participated in at least two of the following nature activities while travelling in Australia: visit national parks or state parks; visit wildlife parks, zoos or aquariums; visit botanical or other public gardens; bushwalking or rainforest walks; whale or dolphin watching (in the ocean); snorkelling; and, scuba diving.

Those who carbon offset were significantly more likely to stay in Australia for more nights $(\mathrm{F}(1,1370)=43.5, \mathrm{P}<0.001)$; generally staying 46 nights on average compared with those who did not carbon offset staying 33 nights. In addition, they were also more likely to have more overnight stopovers (locations where they stayed overnight) while in Australia ( $\mathrm{F}(1$, $1370)=140.22, \mathrm{P}<0.001$ ), generally stopping over in five locations on average compared with three stopovers for visitors who did not offset. They were also significantly more likely to be a member of Tourism Australia's 'experience seeker' segmentation $(F(1,1370)=194.14$, $\mathrm{p}<0.001)$. Further, those who carbon offset were significantly more likely to be a backpacker $(\mathrm{F}(1,1370)=389.52, \mathrm{p}<0.001)$, where backpacker is defined as an international visitor who stayed in backpacker accommodation while travelling in Australia (Tourism Research Australia, 2009). Australia's backpacker market is traditionally a youth market, composed of a high proportion of travellers from the UK and Europe, with 59\% of backpackers originating from these countries. Thus, this finding is perhaps reflective of a broader prevalence of these markets to carbon offset. No significant differences were found in the prevalence of carbon offsetting by gender, flight class and first time versus repeat visitation.

The two-step cluster analysis identified three cluster groups. Table 2 presents summary results of the three clusters. The three clusters were labelled based on their characteristics as "Repeat Asia-Pacific Travellers” (39\% of carbon offsetters), "Middle-aged Leisure Tourists" (38\% of carbon offsetters) and "Young European Backpackers" (23\% of carbon offsetters). It is notable that both "Middle-aged Leisure Tourists" and "Young European Backpackers" are strongly represented by the UK and European markets. The change, if any, of the cluster composition of carbon offsetters over the three years was also investigated. That is, did any of the segments change proportionately in overall size over time? Cluster 1 "Repeat AsiaPacific Travellers" (F(1.99, 2727.07)=6.68, P=0.001) and Cluster 3 "Young European 
Backpackers” $(\mathrm{F}(1.96,2684.57)=15.54, \mathrm{P}<0.001)$ were found to significantly increase as a proportion of carbon offsetters, however, there was no significant change in Cluster 2 “Middle-aged Leisure Tourists” over the three year period $(F(1.99,2720.21)=1.93, P=0.146)$.

\section{<Insert Table 2 about here $>$}

\section{Discussion and Conclusion}

This research has addressed a gap in the literature by offering a comprehensive profile of international visitors who made voluntary carbon offsetting payments related to their travel to or within Australia between 2008 and 2010. Using the IVS data, this analysis identified the characteristics of international travellers to Australia who made a voluntary carbon offset payment and explored whether there was any change in the proportional size of these market segments over time. The results suggest that travellers from the UK were most likely to carbon offset, whereas those originating from Asian countries were less likely to participate in these schemes. This provides some evidence that the social marketing, public discourse and substantial media coverage in the UK and Europe (Doulton \& Brown, 2009; Burchell et al., 2013) may have performed a role in enhancing climate change mitigation behaviours. Should future research establish a more formal link between social marketing and carbon offsetting, an implication would be that an increase in carbon offsetting could be driven by government and industry via marketing.

The results also revealed that voluntary carbon offsetting visitors tend to be travelling for either holiday or employment and were able to be classified as nature based visitors. This indicates that business travellers are less likely to uptake carbon offsetting than individual travellers and thus corporate engagement in offsetting may be low. However, businesses may be contributing to company-wide offset schemes or employees may not be informed of offsetting undertaken on their behalf. Further, despite a Global Financial Crisis (GFC) occurring in 2008, the analysis found no evidence of a decline in the proportion of carbon offsetters between 2008 and 2010, offering evidence of a stable carbon offsetting market. While two time-points following the GFC should be adequate to capture short-term response patterns of carbon offsetters, there is a need for future research to investigate whether the prevalence of carbon offsetting is subject to longer-term behavioural changes as a result of economic crises. Lastly, the two-step cluster analysis identified three distinct segments of carbon offsetters and provided a detailed demographic profile for each cluster.

This research note has several important implications for knowledge and practice. It is of particular importance to companies who provide carbon offsetting schemes because it indicates a relatively stable market for carbon offsetting and delivers critical information surrounding demographics and the trip profile of Australia's international visitors who make voluntary payments to offset their carbon emissions. Thus, this research allows these companies to develop separate and segment-specific strategies and communication messages 
to enhance uptake of carbon offsetting initiatives. The research also raises questions with respect to tourists' sustainable travel behaviour and those who engage in it. The findings may indicate that social marketing and the stage of economic development in a country could influence visitors' sustainable behaviour and mitigation activities. This speculation arose due to the prevalence of carbon offsetting amongst the mature European and UK markets when compared with the emerging growth markets of Asia. This research ultimately indicates a need for more advanced consideration of the link between carbon offsetting behaviour and social marketing, as well as greater research into Asian travellers' environmental perceptions and behaviours. Importantly, questions arise surrounding whether there is an opportunity to grow the carbon off-setting market, with exploratory research into the identified cluster groups being needed to determine if there are inherent characteristics that might limit possible future growth in the market, such as being from wealthier social classes. 


\section{References}

Becken, S. (2002). Analysing international tourist flows to estimate energy use associated with air travel. Journal of Sustainable Tourism, 10(2), 114-131.

Becken, S. (2007). Tourists' perception of international air travel's impact on the global climate and potential climate change policies. Journal of Sustainable Tourism, 15(4), 351-368.

Becken, S. \& Hay, J. (2012). Climate Change and Tourism: From Policy to Practice. London: Routledge.

Burchell, K., Rettie, R., \& Patel, K. (2013). Marketing social norms: Social marketing and the 'social norm approach'. Journal of Consumer Behaviour, 12(1), 1-9.

Dolnicar, S., Crouch, G.I. \& Long, P. (2008). Environment-friendly Tourists: What do we really know about them? Journal of Sustainable Tourism, 16(2), 197-210.

Doulton, H. \& Brown, K. (2009). Ten years to prevent catastrophe? Discourses of climate change and international development in the UK press. Global Environmental Change, 19, 191-202.

Gössling, S. (2009). Carbon neutral destinations: A conceptual analysis. Journal of Sustainable Tourism, 17(1), 17-37.

Gössling, S., Broderick, J., Upham, P., Ceron, J.P., Dubois, G., Peeters, P., \& Strasdas, W. (2007). Voluntary carbon offsetting schemes for aviation: Efficiency, credibility and sustainable tourism. Journal of Sustainable Tourism, 15(3), 223-248.Hares, A., Dickinson, J. \& Wilkes, K. (2010). Climate change and the air travel decisions of UK tourists. Journal of Transport Geography, 18, 566-473.

Mair, J . (2011). Exploring air travellers' voluntary carbon-offsetting. Journal of Sustainable Tourism, 19(2), 215-230.

McKercher, B., Prideaux, B., Cheung, C., \& Law, R. (2010). Achieving voluntary reductions in the carbon footprint of tourism and climate change. Journal of Sustainable Tourism, 18(3), 297-317.

Smith, I. \& Rodger, C. (2009). Carbon emission offsets for aviation-generated emissions due to international travel to and from New Zealand. Energy Policy, 37, 3438-3447.

StataCorp. (2011). svy: tabulate twoway - Two-way tables for survey data. In STATA Survey Data Reference Manual, Release 12 (pp. 135-153). College Station, Texas: Stata Press.

Tourism Australia. (2006). A Uniquely Australian Invitation: The Experience Seeker. Sydney. Retrieved $13^{\text {th }}$ of November 2013 from, http://www.tourism.australia.com/documents/corporate/marketing_experience_factsh eet.pdf

Tourism Research Australia. (2009). Backpacker Accommodation in Australia. Canberra. Retrieved $11^{\text {th }}$ January, 2014, from http://www.tra.gov.au/documents/Snapshots_2009_Backpacker_FINAL.pdf

van Birgelen, M., Semeijn, J., \& Behrens, P. (2011). Explaining pro-environment consumer behavior in air travel. Journal of Air Transport Management, 17(2), 125-128.

Ziegler, A., Schwarzkopf, J. \& Hoffmann, V.H. (2012). Stated versus revealed knowledge: Determinants of offsetting CO2 emissions from fuel consumption in vehicle use. Energy Policy, 40, 422-431. 
Table 1. Prevalence of carbon offsetting by country/region of residence (market)

\begin{tabular}{|l|r|r|r|}
\hline $\begin{array}{l}\text { Country / } \\
\text { Region of } \\
\text { residence }\end{array}$ & $\begin{array}{l}\text { Proportion of } \\
\text { carbon } \\
\text { offsetters }\end{array}$ & $\begin{array}{l}\text { Proportion of } \\
\text { those who did } \\
\text { not carbon } \\
\text { offset }\end{array}$ & $\begin{array}{l}\text { Proportion of } \\
\text { market who } \\
\text { carbon offset }\end{array}$ \\
\hline New Zealand & $16 \%$ & $20 \%$ & $2 \%$ \\
\hline UK & $26 \%$ & $12 \%$ & $6 \%$ \\
\hline Europe & $20 \%$ & $12 \%$ & $5 \%$ \\
\hline Asia & $19 \%$ & $38 \%$ & $1 \%$ \\
\hline USA & $8 \%$ & $9 \%$ & $3 \%$ \\
\hline Canada & $5 \%$ & $2 \%$ & $6 \%$ \\
\hline Other countries & $6 \%$ & $7 \%$ & $2 \%$ \\
\hline Total & $\mathbf{1 0 0 \%}$ & $\mathbf{1 0 0 \%}$ & $\mathbf{3 \%}$ \\
\hline
\end{tabular}


Table 2. Two-step cluster analysis results with input variables and profiling

\begin{tabular}{|c|c|c|c|}
\hline & \multicolumn{3}{|c|}{ Cluster } \\
\hline & 1 & 2 & 3 \\
\hline Cluster Name & $\begin{array}{c}\text { Repeat Asia-Pacific } \\
\text { Travellers }\end{array}$ & $\begin{array}{c}\text { Middle-aged Leisure } \\
\text { Tourists } \\
\end{array}$ & $\begin{array}{c}\text { Young European } \\
\text { Backpackers }\end{array}$ \\
\hline Sample Size & 1,093 & 1,136 & 875 \\
\hline Population Size & 149,400 & 146,700 & 87,100 \\
\hline \multicolumn{4}{|l|}{ Input variables } \\
\hline Backpacker & 9\% are backpackers & $0 \%$ are backpackers & $100 \%$ are backpackers \\
\hline Experience seeker & $\begin{array}{l}\text { 65\% are experience } \\
\text { seekers }\end{array}$ & $\begin{array}{l}\text { 68\% are experience } \\
\text { seekers }\end{array}$ & $\begin{array}{l}73 \% \text { are experience } \\
\text { seekers }\end{array}$ \\
\hline Nature traveller & $1 \%$ are nature travellers & $92 \%$ are nature travellers & $100 \%$ are nature travellers \\
\hline Country group & $\begin{array}{l}\text { 31\% are from New } \\
\text { Zealand } \\
\text { 25\% are from Asia } \\
\end{array}$ & $\begin{array}{l}33 \% \text { are from the UK } \\
20 \% \text { are from Asia } \\
19 \% \text { are from Europe }\end{array}$ & $\begin{array}{l}40 \% \text { are from Europe } \\
30 \% \text { are from the UK }\end{array}$ \\
\hline Age group & $\begin{array}{l}28 \% \text { are } 25 \text { to } 34 \text { years } \\
21 \% \text { are } 35 \text { to } 44 \text { years }\end{array}$ & $\begin{array}{l}24 \% \text { are } 25 \text { to } 34 \text { years } \\
20 \% \text { are } 35 \text { to } 44 \text { years } \\
20 \% \text { are } 45 \text { to } 54 \text { years } \\
\end{array}$ & $\begin{array}{l}47 \% \text { are } 15 \text { to } 24 \text { years } \\
41 \% \text { are } 25 \text { to } 34 \text { years }\end{array}$ \\
\hline \multicolumn{4}{|l|}{ Profiling variables } \\
\hline Purpose of visit & $\begin{array}{c}35 \% \text { are on holiday } \\
28 \% \text { are visiting friends } \\
\text { and relatives } \\
21 \% \text { are business travellers }\end{array}$ & $\begin{array}{c}52 \% \text { are on holiday } \\
28 \% \text { are visiting friends } \\
\text { and relatives }\end{array}$ & $\begin{array}{c}71 \% \text { are on holiday } \\
10 \% \text { are education visitors }\end{array}$ \\
\hline $\begin{array}{l}\text { Previous Visits to Australia } \\
\text { (median) }\end{array}$ & 4 & 1 & 0 \\
\hline Length of stay (median nights) & 9 & 18 & 55 \\
\hline $\begin{array}{c}\text { Number of stopovers in } \\
\text { Australia (locations) (Median) }\end{array}$ & 1 & 3 & 8 \\
\hline Gender & $52 \%$ Male & 51\% Female & 53\% Female \\
\hline Average airfare expenditure\# & $\$ 1,300$ & $\$ 1,880$ & $\$ 1,910$ \\
\hline Average spend in Australia+ & $\$ 2,440$ & $\$ 3,760$ & $\$ 6,590$ \\
\hline On a group tour? & $1 \%$ were on a group tour & $6 \%$ were on a group tour & $2 \%$ were on a group tour \\
\hline
\end{tabular}

\# International visitors' average airfare expenditure during the same three year period was $\$ 1,450$.

+ International visitors’ average expenditure in Australia during the same three year period was \$2,800. 
Appendix A. Predictors of carbon offsetting [carbonoffset] using survey logistic regression

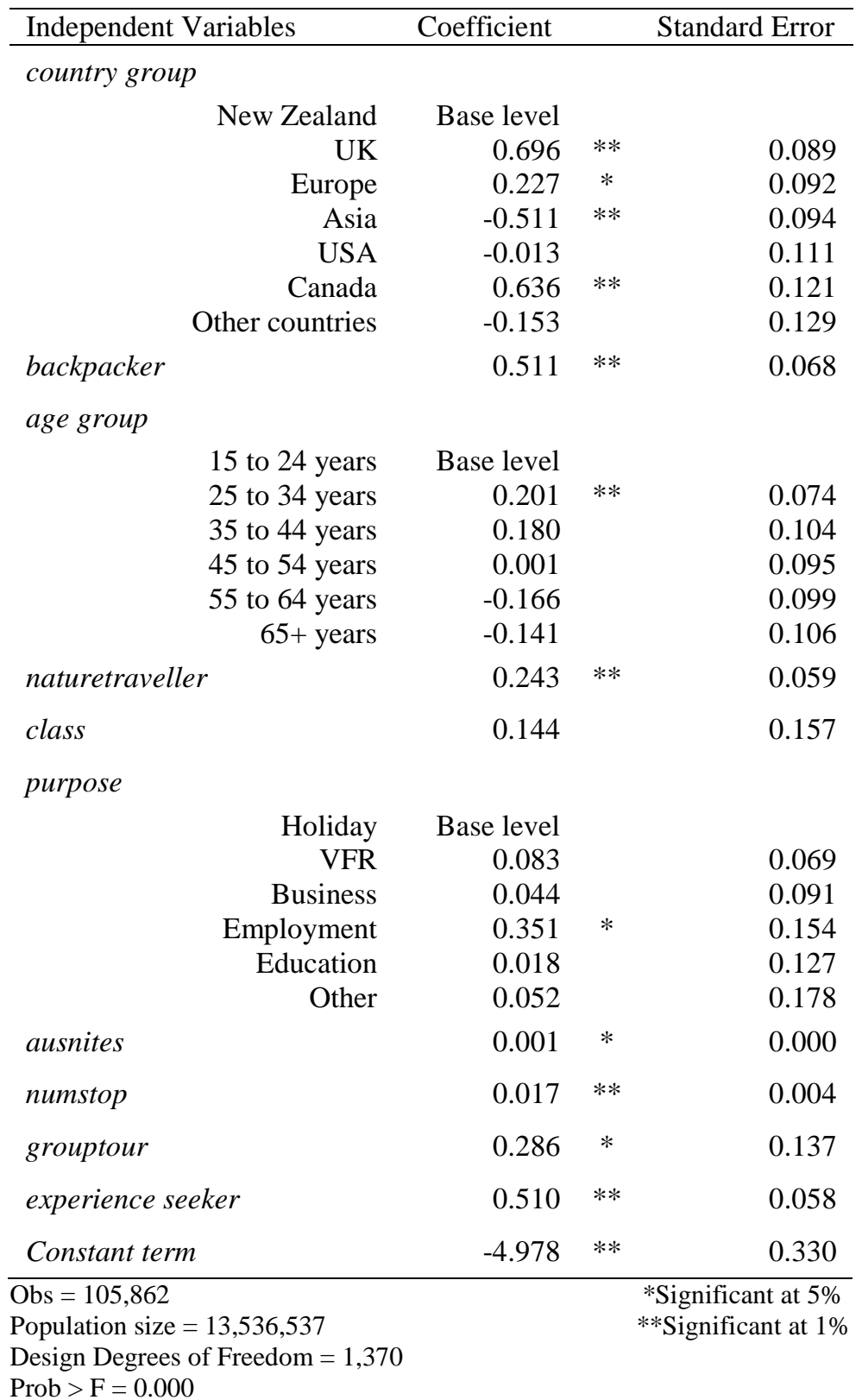

